\title{
Randomized controlled trials of pharmacological treatments to prevent COPD exacerbations: applicability to real-life patients
}

Laurie Pahus ${ }^{1,2,3^{*}}$ (D), Pierre-Régis Burge ${ }^{4,5}$, Nicolas Roche ${ }^{4,5}$, Jean-Louis Paillasseur ${ }^{6}$, Pascal Chanez ${ }^{1,3}$ and on behalf of Initiatives BPCO scientific committee

\begin{abstract}
Background: In patients with chronic obstructive pulmonary disease, all efforts should be made to prevent exacerbations because each event modifies the trajectory of the disease. Treatment recommendations are mostly built on results from randomized controlled trials (RCTs) whose methodology ensure internal validity. However, their relevance may be compromised by the lack of generalizability, due to poor representability of study populations compared to real-life patients.

In order to delimit to whom the results of studies on current and future treatments apply, we sought to identify and characterize the fraction of COPD population that would be eligible for inclusion into RCTs aiming at decreasing exacerbation risk.
\end{abstract}

Methods: We used the Initiatives-BPCO database, a French cohort of 1309 real-life COPD patients monitored in academic centers. We identified industry-sponsored phase III and IV trials that enrolled more than 500 patients, lasted at least one year and used exacerbations related endpoints. Eligibility criteria were extracted from each trial and applied to the patients.

Results: The eligibility criteria of 16 RCTs were applied to the 1309 patients. The most discriminating eligibility criteria were FEV1, minimum exacerbation rate in the previous year and smoking history, responsible for the exclusion of $39.9,36.7$ and $16.8 \%$ of patients, respectively. Altogether, 2.3 to $46.7 \%$ of our patients would have satisfied all eligibility criteria.

Conclusion: These analyses confirm that an important gap exists between real-life patients and clinical trials populations in COPD, which limits the relevance of results and therefore should be considered when grading levels of evidence and designing future studies.

Keywords: Clinical research, External validity, COPD exacerbations

\footnotetext{
* Correspondence: Laurie.Pahus@ap-hm.fr

${ }^{1}$ Clinique des bronches allergies et sommeil, Aix Marseille Univ, APHM, CIC 9502, 13015 Marseille, France

${ }^{2}$ ADES, Aix Marseille Univ, CNRS, EFS, Marseille, France

Full list of author information is available at the end of the article
}

(c) The Author(s). 2019 Open Access This article is distributed under the terms of the Creative Commons Attribution 4.0 International License (http://creativecommons.org/licenses/by/4.0/) which permits unrestricted use, distribution, and reproduction in any medium, provided you give appropriate credit to the original author(s) and the source, provide a link to the Creative Commons license, and indicate if changes were made. The Creative Commons Public Domain Dedication waiver (http://creativecommons.org/publicdomain/zero/1.0/) applies to the data made available in this article, unless otherwise stated. 


\section{Background}

Chronic Obstructive Pulmonary Disease (COPD) is a major public health concern worldwide due to its high prevalence, major impact on health status and elevated costs [1-3]. In most patients, the natural course of the disease is complicated by acute episodes of symptom flares called exacerbations. Frequent exacerbations, especially of the moderate and severe subtypes, have been shown to impair quality of life [4], accelerate the decline in lung function [5] and decrease survival [6].

Each exacerbation has the potential to alter the trajectory of the disease course, increasing the risk for subsequent events $[7,8]$ and shortening the time to the next event [6]. The decisive turning point may be the second severe episode, which delineates a new phase of the disease associated with higher mortality rates [6].

Facing this, all efforts should be made to prevent COPD exacerbations [9]. Several marketed drugs have been shown to decrease the exacerbation rate, and others are currently being tested through randomized controlled trials (RCTs) for this purpose. Treatment recommendations for the management of COPD and related exacerbations are mostly built on these RCTs results [10]. For both scientific community and public opinions, the high level of evidence produced by RCTs drives treatment recommendations and labels the clinical management as "evidence-based".

However, despite a strong methodology ensuring internal validity of results, skepticism about the representativeness of such trials populations towards real-life patients has grown [11-18]. As a consequence of narrow eligibility criteria, efficacy results may not apply to some patients and, more importantly, safety results may underestimate potential side effects. As a result, the importance of real-life evidence to complement RCTs has been emphasized and these study designs have been positioned within a global framework of therapeutic research [19].

The GOLD document on COPD management [10] acknowledges that the lack of external validity may compromise the applicability of trials' results to a broader population. Nonetheless it remains difficult to set apart among the "excluded" patients - the patients who could benefit from a treatment from those who would not.

In order to delimit to whom the results of studies on current and future treatments apply, we sought to identify and characterize patients from a well-characterized reallife hospital-based COPD cohort (Initiatives BPCO) who would be eligible for inclusion into industry-sponsored RTCs on pharmacological treatments of COPD aiming at decreasing exacerbation risk.

\section{Methods}

\section{Patients}

We used the Initiatives-BPCO French cohort, which contained 1309 patients at the time of the present analysis. Patients in this cohort were recruited under stable condition in 18 academic centers in France. Patients recruited in this cohort were aged $\geq 40$ years with spirometry-confirmed diagnosis of COPD, as defined by post-bronchodilator $\mathrm{FEV} 1 / \mathrm{FVC}<0.7$. The exclusion criteria included a predominant diagnosis of asthma, bronchiectasis, or any other significant respiratory disease. Data collection has been extensively described previously [20]. Briefly, a case-report form was used to collect in patient's medical file demographic data, smoking history, physician-diagnosed comorbidities, symptoms, dyspnea (modified Medical Research Council scale), results of pulmonary function tests, and the number of exacerbations and hospitalizations in the previous year. The cohort was approved by the Ethics Committee of Versailles, France (ref 04-479). All patients have provided informed consent for the anonymized recording and analysis of their data.

Selection of RCTs and eligibility criteria.

Using clinicaltrials.com and Pubmed websites, we selected between January 2000 and December 2016 all industry-sponsored phase III and IV RCTs that enrolled more than 500 COPD patients, lasted at least 1 year and aimed at decreasing exacerbations risk. For twin studies, we kept only one study in the analysis. All the eligibility criteria used in these trials were compiled.

\section{Analysis of eligibility of patients with COPD to RCTs}

To determine whether patients recruited in the InitiativesBPCO cohort would have been eligible to RCTs, our analysis first focused on the eligibility criteria per se. It allowed the identification of the most frequently required criteria. By applying criteria to the patients from the Initiatives-BPCO cohort, we were able to assess the share of patients fulfilling each criterion. We could then rank the most discriminating criteria.

The second analysis aimed at applying the set of criteria of each RCT to each patient from the cohort in order to assess the proportion of patients that would be eligible to join each trial (Fig. 1).

The third and final part of the study was to distinguish the eligibility rates of different groups of RCTs differing by their phases of development, pharmacological class of tested agents and starting year.

Several data were not collected or missing in the Initiatives-BPCO database. When this occurred, participants were deemed to remain eligible by the criterion we could not assess. This decision was made in order to avoid underestimating the number of patients that would have been eligible.

All analyses were performed using GraphPad Prism version 7.03 for windows (GraphPad Software, LaJolla California USA, www.graphpad.com). Phases, pharmacological agents and starting years' comparisons were 


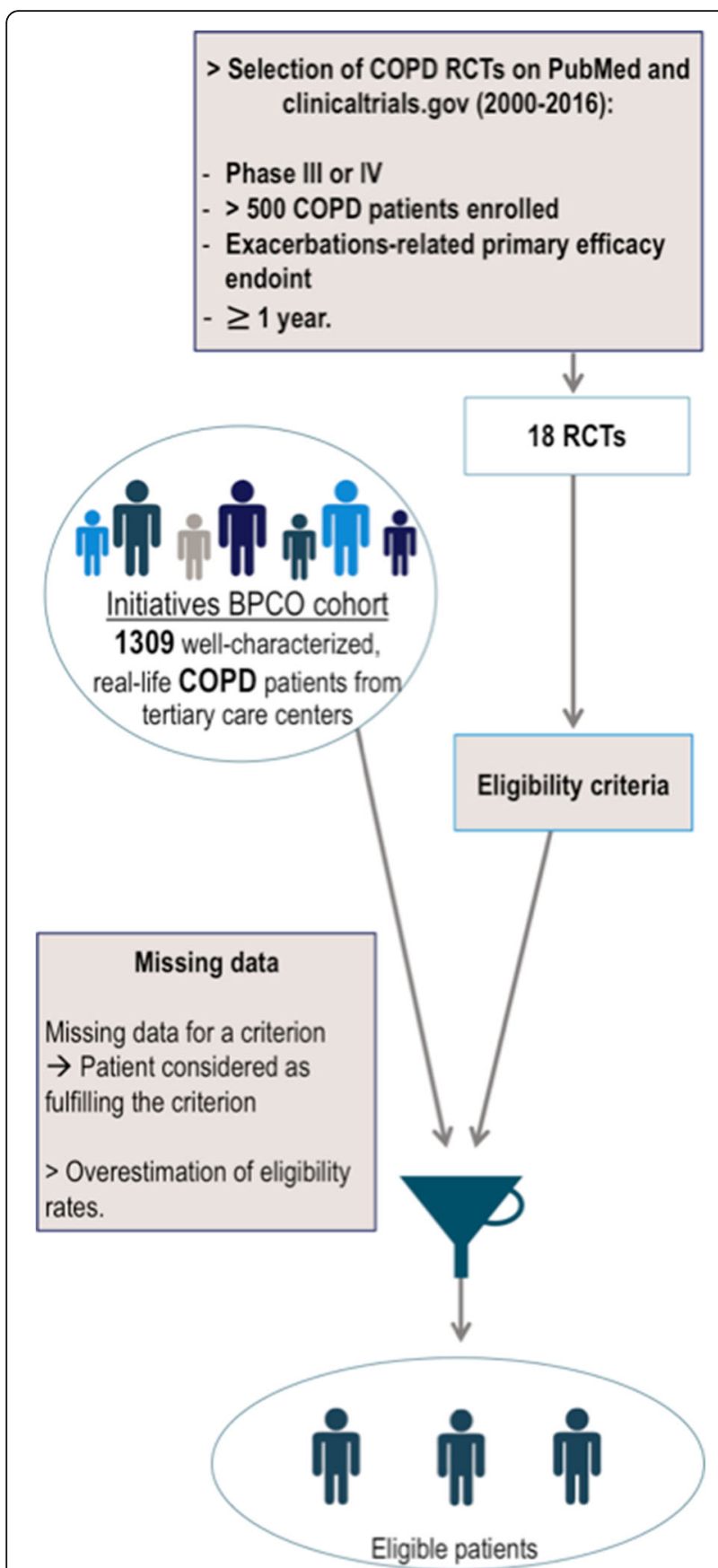

Fig. 1 Methods used to assess the proportion of eligible patients within a real-life hospital-based cohort of COPD patients

performed using Mann-Whitney test, one-way ANOVA followed by Tukey's multiple comparison and KruskalWallis tests, respectively.

\section{Results}

RCTs

The online search for trials provided 16 RCTs fulfilling our criteria (Table 1).
From these 16 RCTs, 11 were phase III trials. The pharmacological agents tested comprised a panel consistent with the different options marketed or being developed in COPD. The distribution of trials based on their starting year covered the whole research timeframe considered for this study (Fig. 2).

\section{Description of eligibility criteria (Table 2)}

\section{Analysis of eligibility rates}

Within our real-life population, eligibility for inclusion into RCTs ranged from 2.3 to $46.7 \%$ of patients depending on the trial with a mean eligibility rate of $16.5 \%$ (95\% CI, 9.2-23.7).

Among all trials, a mean of $39.9 \%$ of our patients would fail because of an FEV1 outside the accepted range. Insufficient exacerbation rate during the previous year would be responsible for the exclusion of $36.7 \%$ of patients. Smoking history criteria would be responsible for the exclusion of patients with a cumulative consumption lower than required (16.8\% of patients). The fourth and fifth most selecting criteria would be comorbidity-related exclusion criteria: cardiovascular comorbidities and asthma restrictions leading to the ineligibility of 16.1 and $11.5 \%$ of patients respectively.

The mean exclusion rates among the 16 trials for criteria related to oxygen therapy, allergic status, diabetes, age, oral corticosteroids intake, upper limit of exacerbations annual rate and history of lung transplant would be less than $6 \%$. (Fig. 3).

\section{Eligibility rates in subgroups of trials}

Phase IV trials $(n=5)$ have a mean eligibility rate of $10.3 \%$ while phase III trials $(n=11)$ have a mean eligibility rate of $19.3 \%$. These results are shown in Fig. 4 along with eligibility rates by pharmacological class of tested agents and starting year of RCTs.

\section{Discussion}

In this large cohort of 1309 well-characterized and followed-up COPD patients from French centers, a majority of patients would not be eligible for enrolment into RCTs assessing the efficacy of pharmaceutical intervention for COPD exacerbations. Importantly, our study described precisely the main reasons for ineligibility in these real-life patients with COPD and illustrate their evolution over 16 years. These data may contribute to the design of future RCTs with the aim of limiting exclusion of patients.

One limitation is the use of an academic cohort as the "real-life" reference. Moreover, enrollment in our cohort is itself limited by some eligibility criteria. We focused on the trials aiming at decreasing the exacerbation risk because they require the enrolment of patients experiencing 


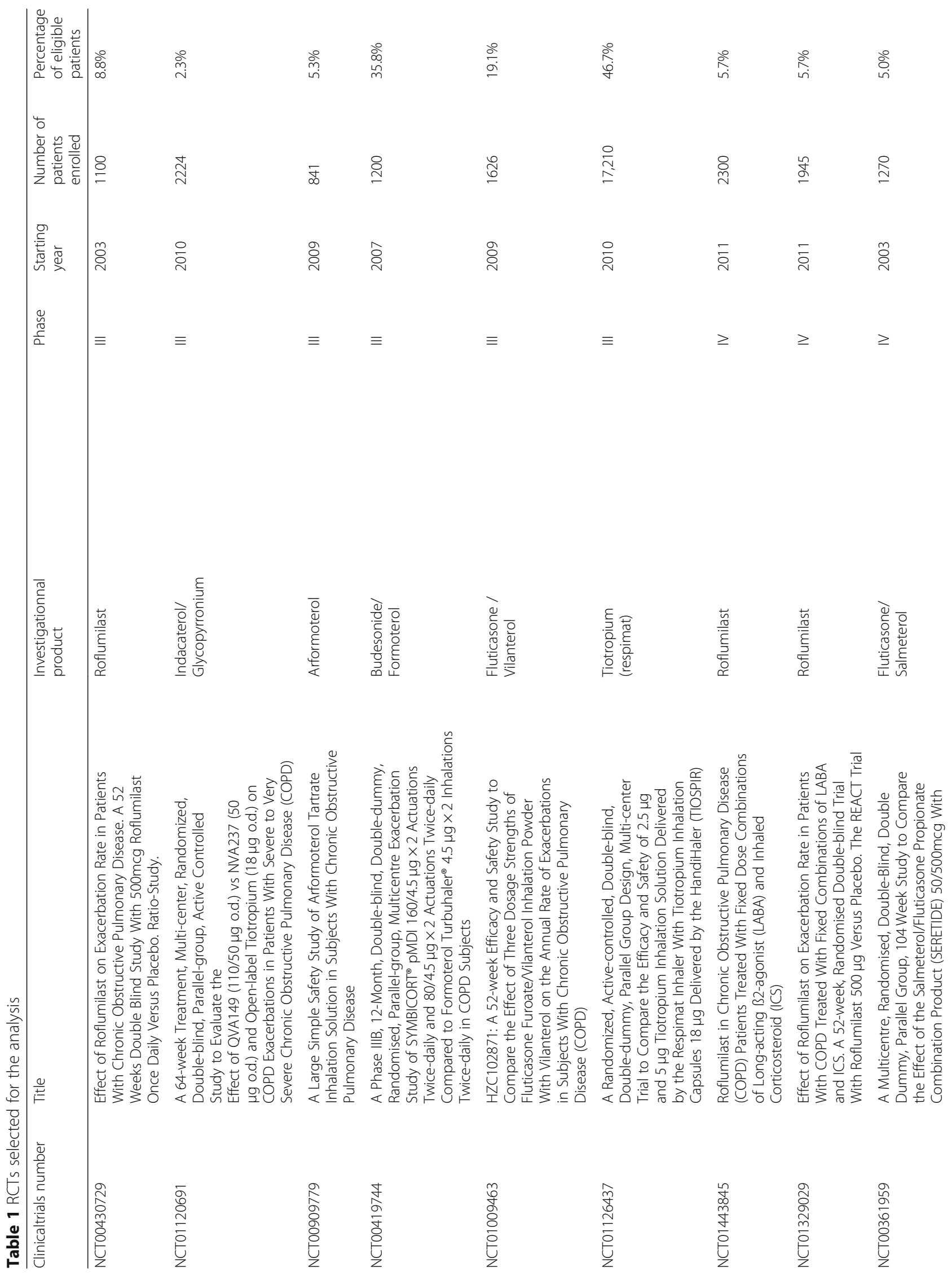




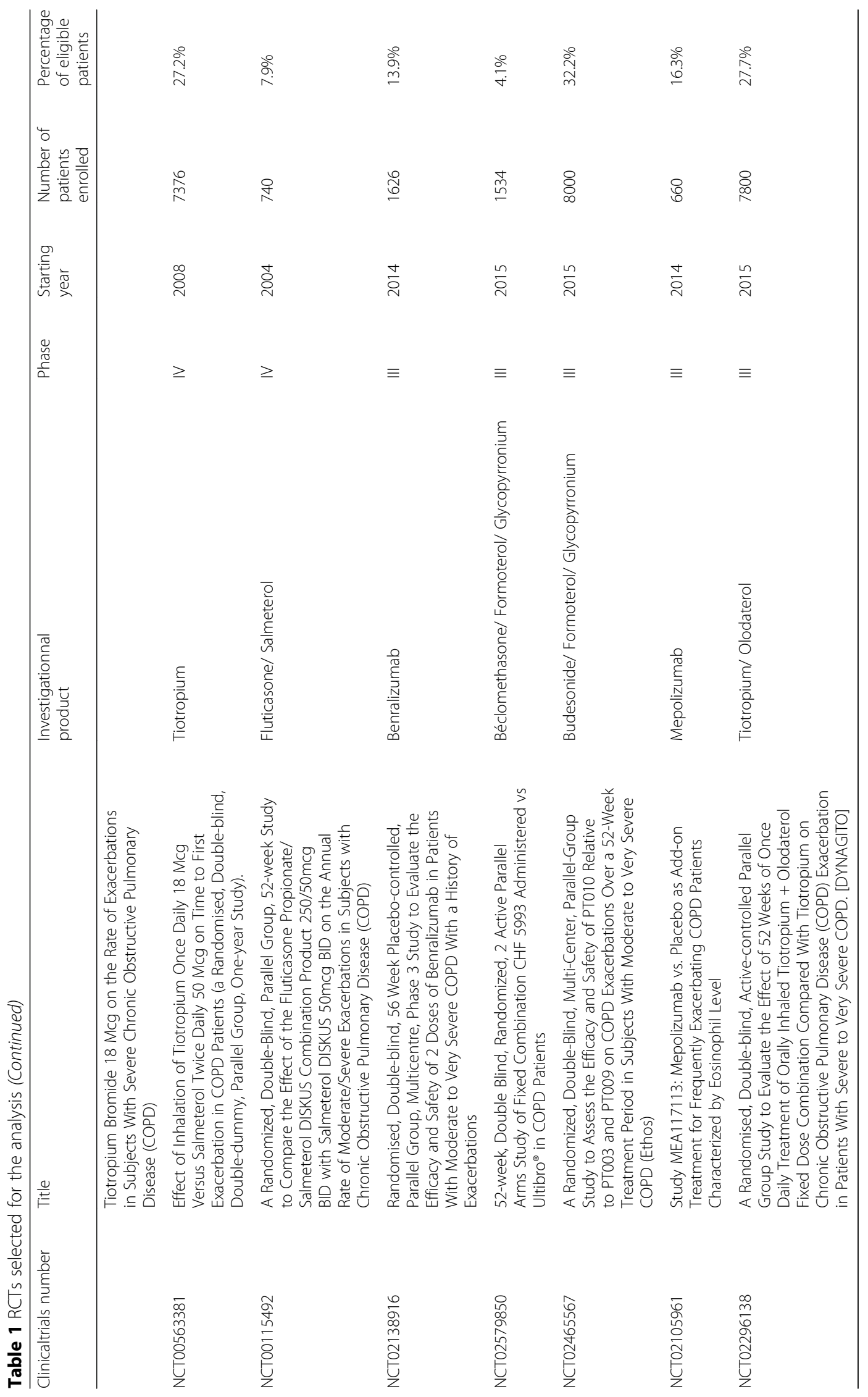




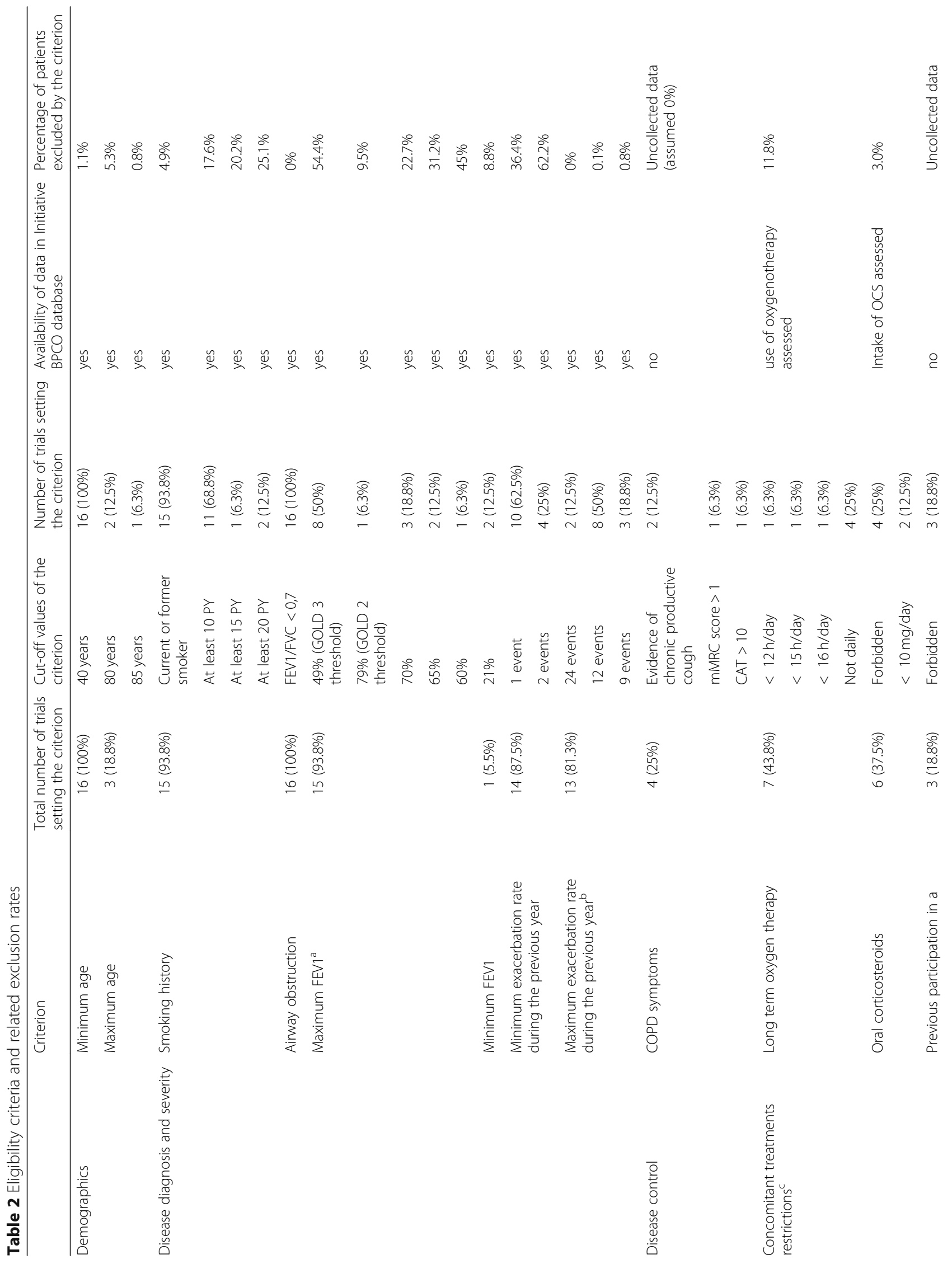




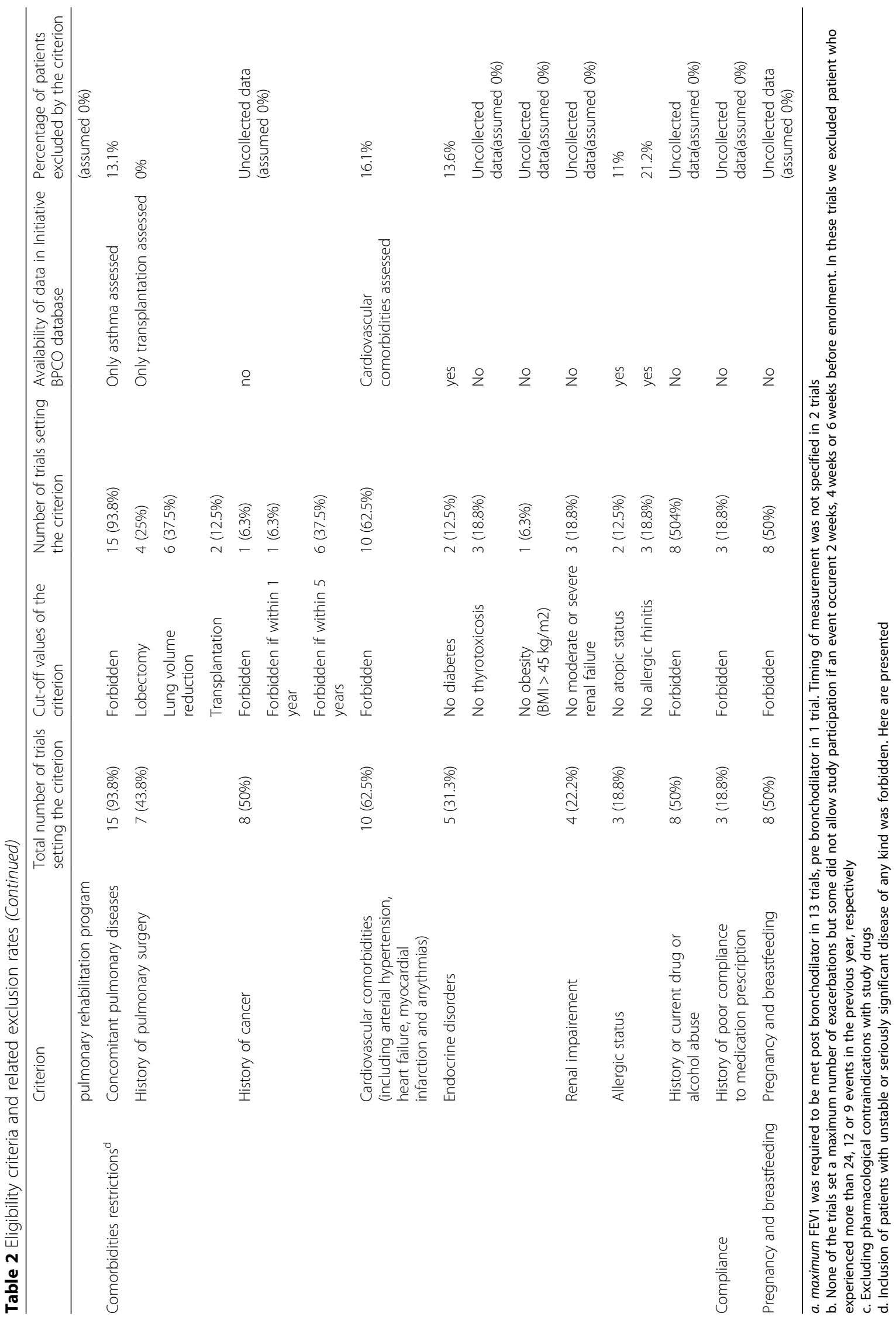


Development phase of selected RCTs

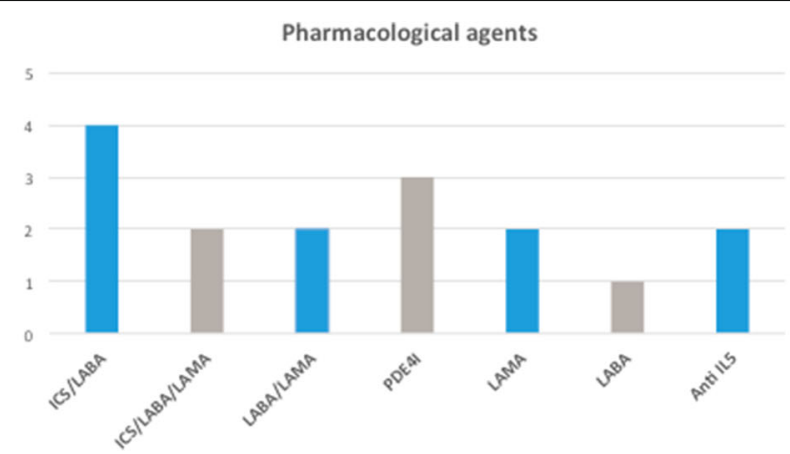

Starting year of RCTs

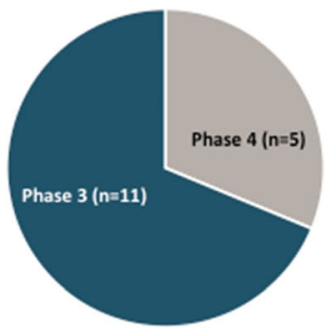

Fig. 2 Characteristics of the RCTs selected for the analysis

severe exacerbations, the patients observed from our cohort being closer to the target population.

We must however acknowledge the potential gap between our cohort and real-life patients. Thus, our eligibility rates may be overestimated but this will not bias our conclusions.

Our findings of eligibility rates ranging from 2.3 to $46.7 \%$ with a mean of $16.5 \%$ are consistent with previously published results: we identified 6 studies dealing with external validity of COPD randomized controlled trials over the last two decades [11-16]. None of them focused specifically on trials aiming at decreasing exacerbation rates but our results are clearly complementary with theirs. Herland applied a limited set of criteria from a fictive "typical RCT" to 366 patients [14]. They found a share of $17.2 \%$ of potentially eligible patients. These results are consistent with those obtained by Kruis (17 to $42 \%$ out of 3508 patients from 7 European primary care databases would have been eligible to enter 6 large industrial RCTs [15]) and our own results. Halpin found eligibility rates ranging from 3.5 to $57.6 \%$ of 36,893 patients from primary and secondary care [11].

Scichilone and Travers both focused on RCTs supporting the old GOLD guidelines for management of COPD in a hospital cohort [12] and in general population [13]. Eligibility rates of $16.9 \%$ and 0 to $9 \%$ respectively show worryingly the impact of the lack of representativity on the recommendations of patients management at the collective level. These results point the poor external validity of many RCTs.

One other limitation is the existence of uncollected data. In this case, a patient was considered fulfilling the missing criterion. This could have resulted in overestimating the eligibility rates. However, with higher eligibility rates than actual rates, our conclusions would even be strengthened. Moreover, we only considered eligibility

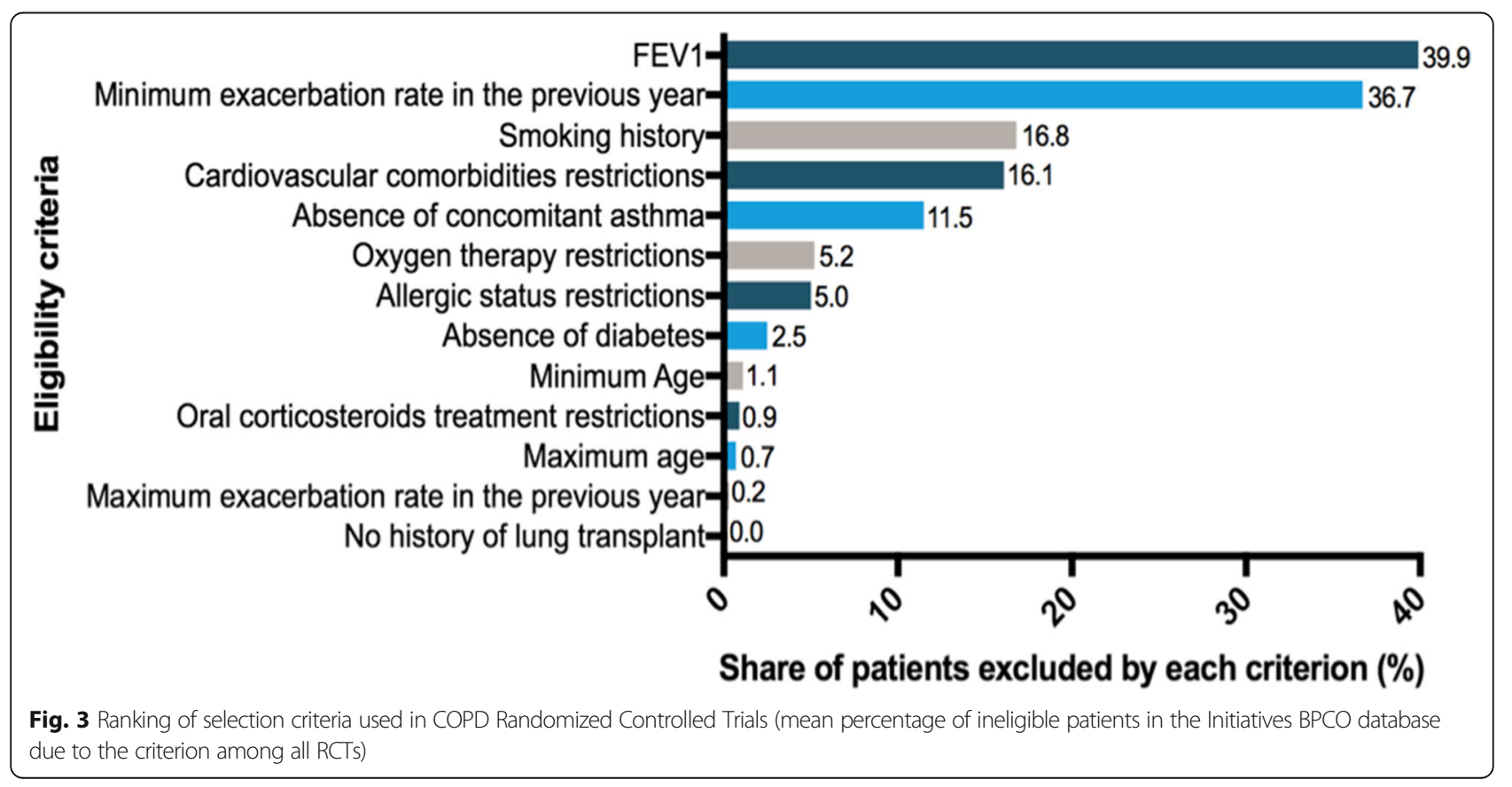




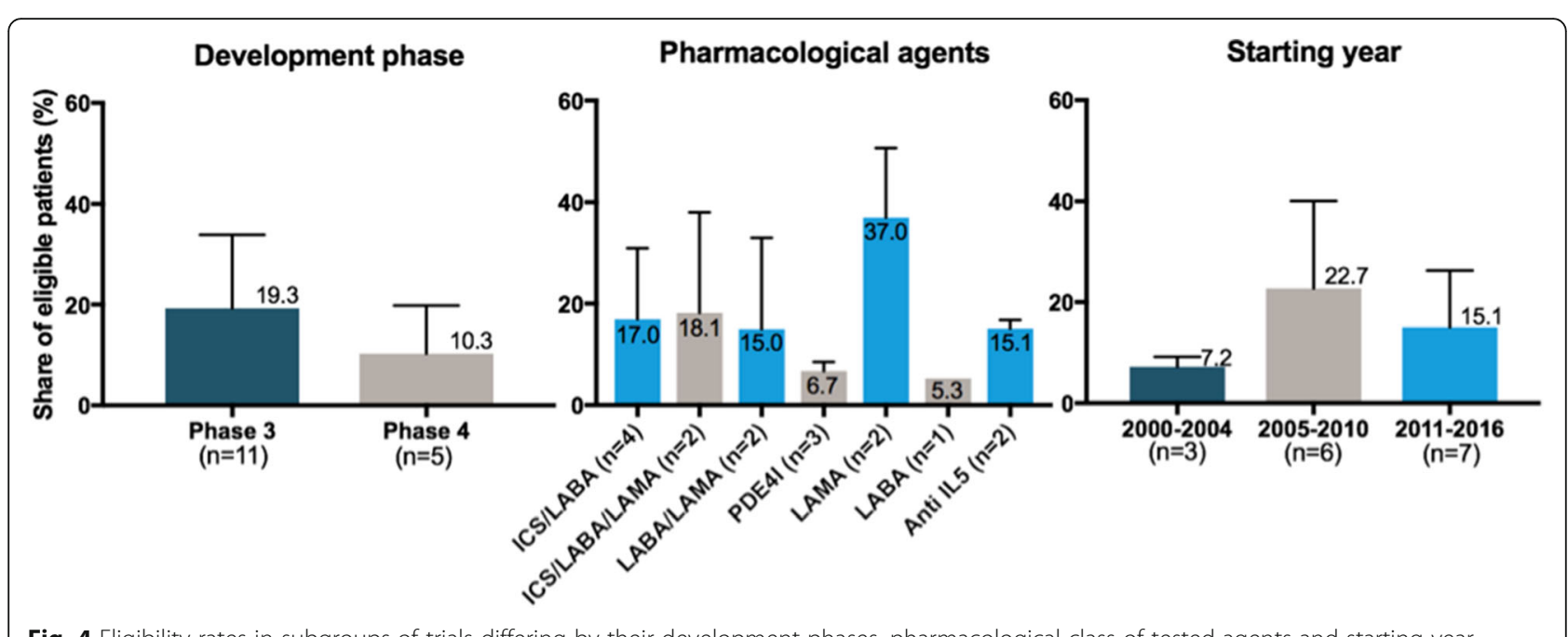

Fig. 4 Eligibility rates in subgroups of trials differing by their development phases, pharmacological class of tested agents and starting year

criteria at inclusion, some run-in or randomization criteria may apply.

Decreasing the number of exacerbations (especially the severe ones) is a major challenge in COPD. Promising results obtained in RCTs often contrast with the modest results observed in daily practice. The evidencebased management of individual patients relies on a meticulous analysis of external validity of RCTs results: Would my patient have been includable in this trial? If not, can I extrapolate the results to my patient considering the unmet criteria?

Some eligibility criteria may have a limited impact on external validity: excluding patients who previously participated in rehabilitation program for example may not exclude a specific sub-population.

Some other criteria are selecting but relevant with regard to the primary endpoint. We focused on RCTs aiming at decreasing the exacerbation risk, which makes it appropriate to enroll patients with a history of exacerbation(s). We must however mention that considering the study primary efficacy endpoint is crucial in the extrapolation of results to a patient. Rothnie and colleagues recently show that almost $52 \%$ of COPD patients do not exacerbate in the first year of follow up and that a $26 \%$ do not exacerbate during a 10 years follow up. Treating these patients with medications that only prove their efficacy on exacerbation rate would not be relevant, but it remains difficult if not impossible to predict the risk of exacerbation accurately on an individual basis [21].

In contrast, some other eligibility criteria are responsible for the exclusion of important sub-populations of patients whose COPD exacerbations triggers and pathophysiology may differ from the ones of enrolled patients.

To illustrate this point, three groups of criteria require particular attention:
First, a selective FEV1-related criterion is set in $94 \%$ of RCTs and would be responsible for the exclusion of $39.9 \%$ of patients from our database. Only one trial allowed the enrollment of patients with mild airflow limitation. To assess medications aiming at decreasing exacerbation risk, most RCTs only allowed the enrollment of patients with severe airflow obstruction, which is not necessarily correlated to exacerbation risk. Another interesting finding of Kruis is the proportion of frequent exacerbators among GOLD 1 patients: $12 \%$ are frequent exacerbators with $\geq 2$ events a year. $34 \%$ have at least 1 event a year. Woodruff has similar findings pointing that COPD exacerbations and symptoms may occur in patient with preserved pulmonary function [22]. We cannot assume that RCTs results are extrapolatable to these patients.

The second set of criteria is related to the potential risk factors for COPD. In 94\% of RCTs in our analysis, only current or former smokers were enrolled. There is no doubt as to the responsibility of tobacco as a risk factor in COPD. However, it is reductive to consider only this risk factor in drug development as COPD may develop in never smokers (up to $27 \%$ in some studies) [23-25].

Similarly, wheezing and a past history of asthma have been shown to be major risk factors for COPD exacerbations $[8,26]$. These patients are excluded from $87 \%$ of RCTs in our study. Thus, patients with an Asthma-COPD overlap are not considered in COPD studies. They are also excluded from asthma studies [18] which makes it difficult to define their management in an evidence-based manner.

Because patients are excluded from RCTs based on risk factors, the pharmaceutical industry does not consider the heterogeneity of patients with COPD in the development of medications [27]. As a correlate, this aspect is poorly considered either during the registration process by regulatory authorities. 
Pathophysiological mechanisms may differ and we cannot assume that RCTs results apply to COPD phenotypes in which they have not been tested.

Lastly, the set of exclusion criteria related to comorbidities raises additional concerns about the applicability of patients' outcomes in RCTs to real-life situations. Cardiovascular comorbidities as well as atopy and diabetes are common barriers to inclusion. These are also highly prevalent in COPD patients, associated to worse outcomes and to different response to therapy. If allergic status and diabetes rates are consistent with previous epidemiologic studies, we found lower cardiovascular comorbidities proportions in our cohort than previously reported $[28,29]$ while these where not exclusion criteria to enter the initiatives-BPCO cohort. Only arterial hypertension, heart failure, myocardial infarction and arrhythmias were collected in our database.

Several comorbidities have been shown to be associated with the "frequent exacerbator" phenotype and to increase the exacerbation risk [30]. This is particularly the case for heart failure, asthma and diabetes, which are all frequent exclusion criteria in RCTs in our study. Excluding patients with higher exacerbation risk is then questionable in studies aiming at decreasing exacerbation risk.

All these restrictions in RCTs lead to poor external validity. It is common belief to think that this gap between trials and real-life populations exists more in phase III than in phase IV trials. We found that phase 4 are also poorly representative.

We could then hypothesize that meta-analyses could help increasing the applicability of results to patients excluded in some but not all studies. However, our results highlight important similarities of eligibility criteria among RCTs. Consequently, tested populations are very homogeneous and meta-analyses cannot fully bridge the gap.

These results emphasize the need for high quality reallife therapeutic research to complement RCTs and determine whether, to which extent and in whom efficacy results translate into real-life effectiveness [31].

\section{Conclusion}

Our study shows that a majority of real-life COPD patients are not eligible for inclusion in RCTs assessing the effects of therapeutic intervention on COPD exacerbations. The excluded populations may present distinct triggers for exacerbations and we cannot assume the applicability of study results to these patients.

This important gap between real-life patients and clinical trials populations limits the external validity of RCTs and therefore should be considered when grading levels of evidence and designing future studies to ensure evidence-based medical decision-making.

\section{Abbreviations}

BMI: Body Mass Index; CAT: COPD Assessment Test; COPD: Chronic Obstructive Pulmonary Disease; FEV1: Forced Expiratory Volume in $1 \mathrm{~s}$; FVC: Forced Vital Capacity; GOLD: Global initiative for chronic Obstructive Lung Disease;

ICS: Inhaled Corticosteroids; IL5: Interleukin 5; LABA: Long Acting Beta2 Agonist; LAMA: Long Acting Muscarinic Antagonist; Mcg: Microgram; mMRC: Modified Medical Research Council; PE4i: Phosphodiesterase type 4 Inhibitor; PY: Pack Year; RCT: Randomized Controlled Trial

\section{Acknowledgements}

Not applicable.

\section{Ethics approval and informed consent to participate}

The cohort was approved by the Ethics Committee of Versailles, France (ref 04479). All patients have provided written informed consent for the anonymized recording and analysis of their data.

\section{Authors' contribution}

Conception and design: LP, PRB, NR, JLP, PC. Database extraction: JLP Analysis and interpretation: LP, PRB, NR, PC. Redaction: LP Corrections: PRB, NR, PC. All the authors have read and approved the final version of the manuscript.

\section{Funding}

The French Initiative BPCO cohort is supported by an unrestricted grant from Boehringer Ingelheim and (until 2015) Pfizer. The funding bodies played no role in the design of the study, collection, analysis, interpretation of data and writing of the manuscript.

\section{Availability of data and materials}

The datasets used and/or analysed during the current study are available from the corresponding author on reasonable request after approval from initiatives BPCO scientific committee.

\section{Consent for publication}

Not applicable.

\section{Competing interests}

LP has no conflicts of interest to report.

PRB reports personal fees from Astra Zeneca, personal fees from Boehringer Ingelheim, personal fees from Chiesi, personal fees from GSK, personal fees from Novartis, personal fees from TEVA, personal fees from Vertex, outside the submitted work.

NR reports grants and personal fees from Boehringer Ingelheim, Novartis, Pfizer and personal fees from Teva, GSK, AstraZeneca, Chiesi, Mundipharma, Cipla, Sanofi, Sandoz, 3 M, Zambon outside the submitted work.

JLP has no conflicts of interest to report.

PC, as an advisory board member, consultant or lecturer, has previously received honoraria or grants from Boehringer Ingeheim, Almirall, Centocor, GSK, MSD, Astra Zeneca, Novartis, Teva, Chiesi, Shering Plough and Amu. None of the latter participated in or had any influence over the present analysis or manuscript.

\section{Author details}

${ }^{1}$ Clinique des bronches allergies et sommeil, Aix Marseille Univ, APHM, CIC 9502, 13015 Marseille, France. ${ }^{2}$ ADES, Aix Marseille Univ, CNRS, EFS, Marseille, France. ${ }^{3}$ C2VN (INSERM U1263, INRA 1260), Aix Marseille Univ, Marseille, France. ${ }^{4}$ Service de Pneumologie, GH Cochin-Broca-Hôtel Dieu, APHP, Paris, France. ${ }^{5}$ Sorbonne Paris Cité, Université Paris Descartes, Paris, France. ${ }^{6}$ EFFI-STAT, Paris, France.

Received: 25 January 2019 Accepted: 19 June 2019

Published online: 12 July 2019

References

1. Rycroft CE, Heyes A, Lanza L, Becker K. Epidemiology of chronic obstructive pulmonary disease: a literature review. Int J Chron Obstruct Pulmon Dis. 2012. https://doi.org/10.2147/COPD.S32330 PubMed PMID: 22927753; PubMed Central PMCID: PMCPMC3422122.

2. Blanchette CM, Dalal AA, Mapel D. Changes in COPD demographics and costs over 20 years. J Med Econ. 2012. https://doi.org/10.3111/13696998. 2012.713880 PubMed PMID: 22812689. 
3. Chapman KR, Mannino DM, Soriano JB, Vermeire PA, Buist AS, Thun MJ, et al. Epidemiology and costs of chronic obstructive pulmonary disease. Eur Respir J 2006 doi: https://doi.org/10.1183/09031936.06.00024505. PubMed PMID: 16387952.

4. Seemungal TA, Donaldson GC, Paul EA, Bestall JC, Jeffries DJ, Wedzicha JA. Effect of exacerbation on quality of life in patients with chronic obstructive pulmonary disease. Am J Respir Crit Care Med. 1998; PubMed PMID: 9603117.

5. Donaldson GC, Seemungal TA, Bhowmik A, Wedzicha JA. Relationship between exacerbation frequency and lung function decline in chronic obstructive pulmonary disease. Thorax. 2002; PubMed PMID: 12324669; PubMed Central PMCID: PMCPMC1746193.

6. Suissa S, Dell'Aniello S, Ernst P. Long-term natural history of chronic obstructive pulmonary disease: severe exacerbations and mortality. Thorax. 2012. https://doi.org/10.1136/thoraxjnl-2011-201518 PubMed PMID: 22684094; PubMed Central PMCID: PMCPMC3505864.

7. Sin DD, Anthonisen NR, Soriano JB, Agusti AG. Mortality in COPD: role of comorbidities. Eur Respir J. 2006. https://doi.org/10.1183/09031936.00133805 PubMed PMID: 17138679

8. Hurst JR, Vestbo J, Anzueto A, Locantore N, Müllerova H, Tal-Singer R, et al. Susceptibility to exacerbation in chronic obstructive pulmonary disease. N Engl J Med. 2010. https://doi.org/10.1056/NEJMoa0909883 PubMed PMID: 20843247.

9. FitzGerald JM. Targeting lung attacks. Thorax. 2011. https://doi.org/10.1136/ thx.2010.156760 PubMed PMID: 21398372

10. From the Global Strategy for the Diagnosis, Management and Prevention of COPD, Global Initiative for Chronic Obstructive Lung Disease (GOLD) 2017. Available from: http://goldcopd.org

11. Halpin DM, Kerkhof M, Soriano JB, Mikkelsen H, Price DB. Eligibility of reallife patients with COPD for inclusion in trials of inhaled long-acting bronchodilator therapy. Respir Res. 2016. https://doi.org/10.1186/s12931016-0433-5 PubMed PMID: 27663386; PubMed Central PMCID: PMCPMC5034631

12. Scichilone N, Basile M, Battaglia S, Bellia V. What proportion of chronic obstructive pulmonary disease outpatients is eligible for inclusion in randomized clinical trials? Respiration. 2014. https://doi.org/10.1159/ 000355082 PubMed PMID: 24281343.

13. Travers J, Marsh S, Caldwell B, Williams M, Aldington S, Weatherall M, et al. External validity of randomized controlled trials in COPD. Respir Med. 2007. https://doi.org/10.1016/j.rmed.2006.10.011 PubMed PMID: 17113277

14. Herland $\mathrm{K}$, Akselsen JP, Skjønsberg OH, Bjermer L. How representative are clinical study patients with asthma or COPD for a larger "real life" population of patients with obstructive lung disease? Respir Med. 2005; PubMed PMID: 15672843

15. Kruis AL, Ställberg B, Jones RC, Tsiligianni IG, Lisspers K, van der Molen T, et al. Primary care COPD patients compared with large pharmaceuticallysponsored COPD studies: an UNLOCK validation study. PLoS One. 2014. https://doi.org/10.1371/journal.pone.0090145 PubMed PMID: 24598945; PubMed Central PMCID: PMCPMC3943905

16. Walker S, Fingleton J, Weatherall M, Beasley R. Limited generalisability of UPLIFT findings to clinical practice. Thorax. 2013. https://doi.org/10.1136/ thoraxjnl-2013-203724 PubMed PMID: 23744029.

17. Travers J, Marsh S, Williams M, Weatherall M, Caldwell B, Shirtcliffe P, et al. External validity of randomised controlled trials in asthma: to whom do the results of the trials apply? Thorax. 2007. https://doi.org/10.1136/thx.2006. 066837 PubMed PMID: 17105779; PubMed Central PMCID:

PMCPMC2117157.

18. Pahus L, Alagha K, Sofalvi T, Vachier I, Bourdin A, Molinari N, et al. External validity of randomized controlled trials in severe asthma. Am J Respir Crit Care Med. 2015. https://doi.org/10.1164/rccm.201502-0391LE PubMed PMID: 26177176.

19. Roche N, Reddel HK, Agusti A, Bateman ED, Krishnan JA, Martin RJ, et al. Integrating real-life studies in the global therapeutic research framework Lancet Respir Med. 2013. https://doi.org/10.1016/S2213-2600(13)70199-1 PubMed PMID: 24461762.

20. Burgel PR, Nesme-Meyer P, Chanez P, Caillaud D, Carré P, Perez T, et al. Cough and sputum production are associated with frequent exacerbations and hospitalizations in COPD subjects. Chest. 2009. https://doi.org/10.1378/ chest.08-2062 PubMed PMID: 19017866.

21. Rothnie KJ, Müllerová H, Smeeth L, Quint JK. Natural history of chronic obstructive pulmonary disease exacerbations in a general practice-based population with chronic obstructive pulmonary disease. Am J Respir Crit
Care Med. 2018. https://doi.org/10.1164/rccm.201710-20290C PubMed PMID: 29474094; PubMed Central PMCID: PMCPMC6118021.

22. Woodruff PG, Barr RG, Bleecker E, Christenson SA, Couper D, Curtis JL, et al. Clinical significance of symptoms in smokers with preserved pulmonary function. N Engl J Med 2016 doi: https://doi.org/10.1056/NEJMoa1505971. PubMed PMID: 27168432; PubMed Central PMCID: PMCPMC4968204.

23. Tan WC, Sin DD, Bourbeau J, Hernandez P, Chapman KR, Cowie R, et al. Characteristics of COPD in never-smokers and ever-smokers in the general population: results from the CanCOLD study. Thorax. 2015. https://doi.org/ 10.1136/thoraxjnl-2015-206938 PubMed PMID: 26048404

24. Denguezli M, Daldoul H, Harrabi I, Gnatiuc L, Coton S, Burney P, et al. COPD in nonsmokers: reports from the Tunisian population-based burden of obstructive lung disease study. PLoS One. 2016. https://doi.org/10.1371/ journal.pone.0151981 PubMed PMID: 27010214; PubMed Central PMCID: PMCPMC4807055

25. Lamprecht B, McBurnie MA, Vollmer WM, Gudmundsson G, Welte T, Nizankowska-Mogilnicka E, et al. COPD in never smokers: results from the population-based burden of obstructive lung disease study. Chest. 2011. https://doi.org/10.1378/chest.10-1253 PubMed PMID: 20884729; PubMed Central PMCID: PMCPMC3168866.

26. Silva GE, Sherrill DL, Guerra S, Barbee RA. Asthma as a risk factor for COPD in a longitudinal study. Chest. 2004. https://doi.org/10.1378/chest.126.1.59 PubMed PMID: 15249443.

27. Koblizek V, Milenkovic B, Barczyk A, Tkacova R, Somfay A, Zykov K, et al. Phenotypes of COPD patients with a smoking history in central and Eastern Europe: the POPE study. Eur Respir J. 2017. https://doi.org/10.1183/ 13993003.01446-2016 PubMed PMID: 28495687; PubMed Central PMCID: PMCPMC5460642

28. Putcha N, Drummond MB, Wise RA, Hansel NN. Comorbidities and chronic obstructive pulmonary disease: prevalence, influence on outcomes, and management. Semin Respir Crit Care Med. 2015. https://doi.org/10.1055/s0035-1556063 PubMed PMID: 26238643; PubMed Central PMCID: PMCPMC5004772.

29. Smith MC, Wrobel JP. Epidemiology and clinical impact of major comorbidities in patients with COPD. Int J Chron Obstruct Pulmon Dis. 2014. https://doi.org/10.2147/COPD.S49621 PubMed PMID: 25210449; PubMed Central PMCID: PMCPMC4154888.

30. Westerik JA, Metting El, van Boven JF, Tiersma W, Kocks JW, Schermer TR. Associations between chronic comorbidity and exacerbation risk in primary care patients with COPD. Respir Res. 2017. https://doi.org/10.1186/s12931017-0512-2 PubMed PMID: 28166777; PubMed Central PMCID: PMCPMC5294875

31. Roche N, Reddel H, Martin R, Brusselle G, Papi A, Thomas M, et al. Quality standards for real-world research. Focus on observational database studies of comparative effectiveness. Ann Am Thorac Soc. 2014. https://doi.org/10. 1513/AnnalsATS.201309-300RM PubMed PMID: 24559028.

\section{Publisher's Note}

Springer Nature remains neutral with regard to jurisdictional claims in published maps and institutional affiliations.

Ready to submit your research? Choose BMC and benefit from:

- fast, convenient online submission

- thorough peer review by experienced researchers in your field

- rapid publication on acceptance

- support for research data, including large and complex data types

- gold Open Access which fosters wider collaboration and increased citations

- maximum visibility for your research: over $100 \mathrm{M}$ website views per year

At BMC, research is always in progress.

Learn more biomedcentral.com/submissions 